\title{
A LINGUAGEM ESCRITA NOS CURSOS DE GRADUAÇÃo EM QUÍMICA
}

\author{
Salete Linhares Queiroz*
}

Instituto de Química de São Carlos, Universidade de São Paulo, CP 780, 13560-970 São Carlos - SP

Recebido em 1/7/99; aceito em 16/5/00

\begin{abstract}
WRITING IN CHEMISTRY COURSES. There is no question that students majoring in chemistry graduate with underdeveloped writing skills. Many educators have expressed concern about the obvious deficiencies in student writing. This article is designed to aid professors interested in teaching writing skills in their classrooms and laboratories.
\end{abstract}

Keywords: writing to learn; communication skills; writing assignments.

\section{INTRODUÇÃO}

Menções sobre a flagrante dificuldade encontrada pelos estudantes de graduação em química na comunicação dos seus conhecimentos são constantemente feitas em revistas especializadas de educação em ciências ${ }^{1-4}$. No caso particular da comunicação de idéias através da linguagem escrita verifica-se um agravamento considerável no grau destas dificuldades. Como o campo da química é potencialmente quantitativo, os currículos dos cursos de química no ensino superior, de uma forma geral, enfatizam o desenvolvimento de habilidades quantitativas, como a efetuação de cálculos e resolução de problemas, em prejuízo do desenvolvimento de habilidades qualitativas, como a escrita. Além disto, o uso freqüente da linguagem matemática por parte dos alunos conspira para que esta situação se fortaleça.

Indubitavelmente, a capacidade de escrever bem é extremamente importante para uma carreira de sucesso em ciências e em outras profissões. Assim, esta dificuldade que alguns alunos de química apresentam, em parte como um reflexo da formação recebida na universidade, pode ser limitante para o seu futuro. Tomando-se como exemplo a carreira de um cientista, que muitos alunos de química estão fadados a seguir, pode-se dizer que a sua reputação, o seu salário e desenvolvimento profissional são fortemente influenciados pelo seu trabalho escrito, que inclui a redação de relatórios, artigos científicos e de projetos para solicitação de recursos a agências financiadoras, etc.

$\mathrm{Na}$ tentativa de eliminar, ou pelo menos amenizar, esta dificuldade no uso da linguagem escrita constatada entre alguns estudantes de química, muitas estratégias de ensino, usadas tanto em sala de aula como no laboratório, são reportadas na literatura ${ }^{5}$. Neste artigo pretende-se fazer uma síntese de algumas destas estratégias e comentar os resultados alcançados no que tange ao aprimoramento, ou não, da linguagem escrita a partir da utilização das mesmas. Pretende-se ainda, apresentar estratégias que usam a linguagem escrita como ferramenta para a melhor compreensão dos conceitos pelos alunos e/ou como recurso para facilitar a comunicação entre os alunos e o professor.

\section{ALGUMAS ESTRATÉGIAS DE ENSINO USADAS EM SALA DE AULA}

O uso da linguagem escrita como ferramenta para melhorar a compreensão dos conceitos pelos estudantes e facilitar a comunicação entre alunos e professor, é constante em salas de

*pós-doutoranda do IQSC-USP aulas numerosas, onde se verifica com freqüência o pouco envolvimento dos alunos com a disciplina ${ }^{6-8}$. De fato, o papel dos estudantes nestas salas de aulas é mais passivo e descompromissado do que em outras onde a discussão e o diálogo são mais acessíveis. A estratégia apontada por M. Strauss e T. Fulwiler ${ }^{6}$ para amenizar os efeitos nefastos desta situação baseou-se na tentativa de estimular os estudantes a formular tantas questões sobre o tópico em pauta quanto possível. Estas questões, de caráter anônimo, podiam ser formuladas antes, durante ou depois da aula pelos alunos, colocadas em uma "caixa-de-dúvidas" e lidas após a aula pelo professor, que selecionava algumas delas e tentava incorporá-las no contexto da aula seguinte. As questões eram, nesta ocasião, projetadas na íntegra, com o auxílio de transparências, e solucionadas, conduzindo a um processo em que todos os alunos se beneficiavam de questões apresentadas apenas por alguns deles. $\mathrm{O}$ fato da questão ser apresentada pelo professor, mantendo a linguagem e o simbolismo usado pelo aluno que a submeteu, mantinha a classe envolvida na sua resolução. Além destes resultados satisfatórios, gerados pela estratégia, pode-se citar ainda a possível utilização das perguntas constantes na "caixa-de-dúvidas", e que não foram respondidas em sala de aula, como questões que podiam ser colocadas nas aulas que antecediam o período de provas, comumente chamadas de "aulas para tirar dúvidas". Sobre a estratégia de M. Strauss e T. Fulwiler ${ }^{6}$ cabe ainda salientar a importância que os autores atribuíram ao fato das questões apresentadas serem anônimas, o que tornava o aluno menos inibido e mais propenso a colocar suas dúvidas do que se, eventualmente, a sua identificação fosse solicitada pelo professor.

H. Beall ${ }^{7}$ também valeu-se do uso da escrita em suas aulas para turmas numerosas de química geral no Instituto Politécnico Worcester, no estado de Massachusetts. Em algumas destas ocasiões foi solicitada aos alunos a resolução, por escrito, de uma questão colocada no quadro pelo professor. Esta questão devia ser respondida em um intervalo de 5 minutos e tinha como característica o fato de versar sobre um assunto já ministrado aos alunos, ou seja, era uma questão de revisão. De forma similar ao sugerido por M. Strauss e T. Fulwiler $^{6}$, o professor H. Beall selecionava algumas das respostas apresentadas pelos alunos e projetava-as fazendo uso de transparências, na aula seguinte. Como observado na estratégia anterior, a atenção que os alunos devotavam à disciplina foi acentuada e alguns benefícios adicionais foram observados. Dentre eles, pode-se mencionar que, devido ao caráter de revisão das questões, as mesmas funcionaram como uma auto-avaliação para os alunos. Além disto, algumas resoluções apresentadas eram muito interessantes e enriqueceram consideravelmente o conteúdo da aula. 
Como resultado da análise destas estratégias, direcionadas para salas de aulas numerosas, pode-se concluir que foram bem sucedidas no que diz respeito a provocar uma maior motivação dos alunos em sala de aula e a propiciar uma maior interação professor-aluno. Em ambos os casos, qualquer aperfeiçoamento na linguagem escrita dos aprendizes foi circunstancial. No entanto, inúmeras e variadas são as estratégias voltadas para este objetivo e algumas delas serão comentadas a seguir ${ }^{9-11}$.

Estratégias de ensino, que são aplicadas na tentativa de alcançar o aperfeiçoamento da linguagem escrita dos alunos de graduação, incluem a solicitação da leitura de textos literáriocientíficos e posterior redação de trabalhos sobre o material lido ${ }^{9}$, a inclusão não apenas do conteúdo científico como critério de avaliação em provas (considerações sobre gramática e construção das sentenças são também importantes ${ }^{10}$ ), a descrição por escrito de como um problema químico foi solucionado ${ }^{11}$, etc.

H. Beall ${ }^{9}$ selecionou textos literário-científicos como John Priestley, de T. H. Huxley e Valência e Tautomerismo de W.C. Bray e G.E.K. Branch, entre outros, e solicitou a leitura dos referidos textos aos alunos que, concluída esta tarefa, deveriam escrever uma redação, respondendo a questões sobre o tema lido. Tomando-se como exemplo o texto Valência $e$ Tautomerismo, questões como as citadas a seguir foram apresentadas pelo professor: (1) por que os químicos orgânicos e inorgânicos usam diferentes termos para discutir valência? Explique as diferenças; (2) como o artigo seria modificado se W.C. Bray e G.E.K. Branch soubessem, naquela época, o que você sabe hoje? Como resultado desta estratégia verificou-se que as redações escritas pelos alunos variavam consideravelmente no que dizia respeito à profundidade e clareza de pensamento que refletiam. De uma maneira geral, a gramática e ortografia eram satisfatórias.

N. VanOrden ${ }^{11}$ sugeriu tarefas escritas relacionadas aos conceitos que estavam sendo estudados e que também abordassem problemas do cotidiano. A maioria delas era solucionada em 4 etapas: (1) os alunos precisavam decidir qual informação era necessária para solucionar um problema; (2) encontrar a informação necessária; (3) usar a informação para resolver o problema; (4) justificar a escolha da informação usada para solucionar o problema. Problemas do tipo a seguir eram colocados para os alunos nesta estratégia: você é o gerente de uma loja de animais domésticos. Uma cliente está muito preocupada porque os seus peixes estão morrendo. Quando ela traz para você uma amostra da água onde os peixes vivem, você descobre que o seu $\mathrm{pH}$ é 8,2. Porém, esta espécie de peixe vive melhor em água onde o $\mathrm{pH}$ é 6,8 . (1) Selecione um sistema tampão adequado para um peixe deste tipo. (2) Calcule a quantidade de componente tampão que deve ser adicionado à água para manter o pH igual a 6,8. (3) Escreva uma carta para a cliente explicando como ela deve tratar o seu peixe. Tarefas escritas desta natureza forçaram o aluno a pensar em conceitos químicos e a relacionar estes conceitos com o mundo real. Além disto, era comum que na resolução destas tarefas (que exigiam raciocínio aguçado e eram desafiadoras) os alunos dialogassem entre si, estimulando assim uma maior sociabilização em sala de aula. Por fim, ao final da disciplina a escrita dos alunos melhorou sensivelmente, alguns deles se tornaram muito criativos e compreenderam que, de fato, como se escreve é muito importante.

Um exemplo de estratégia que tenta melhorar a escrita dos alunos considerando a nota que será atribuída a cada um deles é encontrado no artigo "Requiring Good Writing in Chemistry Courses" de E. K. Meislich ${ }^{10}$. Em todos os exames a professora incluiu pelo menos uma questão que requeria uma resposta escrita. Os estudantes eram avisados que suas respostas deviam ser escritas em inglês "aceitável" para que contabilizassem créditos. Se a professora decidia que uma resposta cientificamente correta estava escrita de forma inadequada, o aluno não recebia créditos pela mesma, até que fosse redigida novamente em inglês correto . O estudante tinha uma semana para devolver a questão reelaborada à professora. E.K. Meislich ${ }^{10}$ observou que no primeiro exame aplicado $10-15 \%$ dos alunos tiveram suas questões devolvidas para correção. No entanto, uma vez que os estudantes aceitavam o fato de que respostas corretas, porém escritas de forma inadequada, não eram válidas, a maioria deles passou a redigir mais cuidadosamente.

\section{ALGUMAS ESTRATÉGIAS DE ENSINO USADAS EM LABORATÓRIO}

Uma outra abordagem é freqüentemente encontrada na literatura quando se trata de tentar aprimorar a escrita dos alunos de ciências em geral e de química, em particular. Nesta abordagem toma-se como base as atividades realizadas pelos alunos em laboratórios de ciências ${ }^{12-14}$. Em algumas universidades as atividades de laboratório são avaliadas considerando-se a discussão de tópicos específicos, a resolução de problemas, cálculos, etc enquanto que em outras uma descrição formal da experiência deve ser apresentado em relatório. Acredita-se que estimular os alunos a confeccionar um relatório atentando tanto para o seu conteúdo científico e desenvolvimento lógico das idéias quanto para o seu formato e estilo de escrita (gramática, ortografia, construção de sentenças) pode conduzir a resultados compensadores. Seguindo esta tendência R.A. Bailey e C. Geisler $^{15}$ sugeriram que seus alunos apresentassem os relatórios no formato de uma revista científica (J. Am. Chem. Soc., Inorg. Chem., J. Phys. Chem., etc). Estes relatórios eram inicialmente corrigidos por alunos de pós-graduação do Departamento de Língua, Literatura e Comunicação da mesma universidade, chamados de "consultores de escrita" e, em seguida, devolvidos aos alunos para correção e entrega ao professor responsável pela disciplina. Os "consultores de escrita" observavam os aspectos de gramática, estruturação de sentenças, etc e também consideravam o formato usual de um artigo científico e o que cada tópico deveria conter (Resumo, Introdução, Parte Experimental, Resultados e Discussão, Referências Bibliográficas). Os autores observaram que os relatórios apresentados após a aplicação desta estratégia eram redigidos de forma muito mais aprimorada do que os escritos antes da adoção deste sistema. Eles perceberam que podiam avaliar melhor os argumentos científicos apresentados e que os estudantes estavam escrevendo mais efetivamente. Os relatórios mostraram com clareza que as sugestões dos consultores geraram efeitos altamente positivos. O auxílio dos "consultores de escrita" é também mencionado no artigo de B. Y. Stewart ${ }^{16}$, no qual a estratégia usada é muito similar à citada anteriormente e foi igualmente bem sucedida.

Uma prática comum no meio acadêmico, a leitura de artigos científicos por colegas de profissão (buscando-se um produto final mais bem acabado, a partir das considerações e sugestões feitas a respeito do trabalho), inspirou o professor J. L. Koprowski ${ }^{17}$ a desenvolver uma estratégia de ensino bastante criativa nas suas aulas de laboratório. O processo era desencadeado pela solicitação da apresentação de um relatório, no formato padrão, da aula prática realizada. Este relatório era então corrigido pelo professor, que fazia várias colocações, tanto de cunho editorial como científico, e devolvia os relatórios para que fossem corrigidos pelos alunos e novamente devolvidos ao professor para apresentação da nota. A oportunidade de reescrever o relatório foi relevante no processo pois permitiu aos alunos rever criticamente a sua própria escrita e integrar as sugestões do professor. O segundo relatório apresentado recebeu um código e teve a folha de rosto (onde se encontra a identificação do aluno) removida; nesta ocasião a cada estudante foi dado um pseudônimo. Concluída esta etapa da estratégia, cada estudante recebeu dois relatórios de colegas para que fizesse sugestões, críticas e colocações de âmbito editorial e de caráter científico. Finalmente, o professor desempenhou o papel de um editor de 
revista, avaliando a qualidade dos revisores (os alunos, nesta situação), avaliando os comentários feitos por eles sobre os relatórios dos colegas, apontando colocações equivocadas e dando notas aos relatórios. Esta experiência foi amplamente aceita pelos alunos e considerada muito útil para o desenvolvimento da capacidade de escrita dos mesmos.

\section{UMA BIBLIOGRAFIA RECENTE (1993-1998) SOBRE O USO DA LINGUAGEM ESCRITA NOS CURSOS DE GRADUAÇÃO EM QUÍMICA}

Com o intuito de proporcionar ao leitor uma visão abrangente e atual sobre trabalhos reportados na literatura e que se encontram diretamente relacionados às questões abordadas neste artigo, resumos de algumas referências bibliográficas recentes são apresentados a seguir.

\section{Required Writing in Freshman Chemistry Courses ${ }^{18}$}

Acreditando que "as habilidades mais importantes que os alunos podem desenvolver na universidade são o pensamento crítico e a comunicação clara", S.G. Sunderwirth ${ }^{18}$ apela para o uso intensivo da escrita nas disciplinas que ministra para turmas com até 35 alunos matriculados. Em uma destas turmas, da disciplina de química geral, o autor solicitou aos estudantes que selecionassem 5 tópicos sobre um tema abrangente como, por exemplo, química nuclear e que apresentassem pequenas redações sobre os mesmos. Estas tarefas escritas constituíam $40 \%$ da nota final da disciplina. Neste curso esperava-se que os estudantes selecionassem tópicos apropriados e fossem capazes de desenvolvê-los, incluindo as suas opiniões pessoais. As redações foram avaliadas considerando a clareza da apresentação, estruturação das sentenças, desenvolvimento do tema e a gramática.

\section{Writing - An Approach for Large-Enrollment Chemistry Courses ${ }^{19}$}

O número médio de alunos nas salas de aulas do curso introdutório de química na Clemson University, na Carolina do Sul, é de 200. Esta realidade levou a professora M.M. Cooper ${ }^{19}$ a aplicar tarefas escritas nas suas turmas, na tentativa de aprimorar a sua comunicação com os estudantes. As tarefas solicitadas eram curtas para permitir a leitura das mesmas e a avaliação da professora. De uma forma resumida, pode-se dizer que os alunos mostraram-se satisfeitos com o tipo de tarefas sugerido, melhoraram suas performances em sala de aula e o envolvimento professor-aluno foi acentuado.

\section{Creative Learners in Physical Chemistry and Modern Physics ${ }^{20}$}

A preocupação com a formação de estudantes aptos a solucionar problemas e a analisar situações usando a sua propria lógica dedutiva norteia a discussão deste artigo de L. L. $\mathrm{Combs}^{20}$. O uso da escrita é apresentado como um recurso capaz de desenvolver a capacidade criativa dos alunos de fisico-química e física moderna. $O$ autor solicitou aos seus alunos que eles selecionassem um artigo recente da revista Journal of Chemical Education ou Physics Today, relacionado ao programa das mencionadas disciplinas. Um seminário de 15 minutos e uma redação sobre o tema escolhido eram apresentados pelos alunos. A fim de despertar a atenção dos estudantes para a apresentação e redação dos colegas, um exame final contendo questões sobre cada tema discutido era aplicado.

\section{Writing to Learn in an Organic Chemistry Course ${ }^{21}$}

Neste artigo o autor descreveu como utilizou a linguagem escrita na disciplina de química orgânica. Os estudantes (cerca de 60 alunos das áreas de agricultura, saúde e engenharia) solucionavam problemas quase semanalmente e explicavam suas respostas na forma de redações. Entre as várias vantagens oriundas do emprego desta estratégia, pode-se mencionar que a requisição de respostas escritas, particularmente nesta disciplina em que uma série de mecanismos de reações químicas são estudadas, evitou a simples memorização das várias etapas das referidas reações. Ao final do semestre o professor e os alunos envolvidos nesta experiência julgaram-na altamente positiva e destacaram a efetiva comunicação estabelecida em classe, a partir das constantes discussões geradas a partir da resolução das tarefas escritas.

\section{Probing Student Misconceptions in Thermodynamics With In-Class Writing 22}

Tarefas escritas foram ministradas durante uma disciplina de química geral no Instituto Politécnico Worcester com o intuito de detectar concepções errôneas dos estudantes. Exemplos do uso deste método no ensino do tópico "termodinâmica" foram apresentados neste artigo. Entre os problemas identificados estão a compreensão dos conceitos de calor e temperatura e o entendimento da teoria cinética dos gases. Com relação aos conceitos de calor e temperatura, por exemplo, observações como "calor e temperatura são a mesma coisa, ou seja, a temperatura de um objeto é a quantidade de calor que ele possui" foram feitas pelos alunos. Alguns dos problemas identificados pelos autores eram esperados, enquanto outros surpreenderam.

\section{Using the World Wide Web To Enhance Writing Assignments in Introductory Chemistry Courses ${ }^{23}$}

Nesta estratégia, para a resolução das tarefas escritas solicitadas aos alunos fazia-se necessário o acesso às informações presentes na internet. Após a leitura das informações constantes na internet sobre um determinado assunto, os alunos redigiam um pequeno artigo de revisão. O uso da internet conduziu a uma amplo e variado número de informações dificilmente encontrado em uma biblioteca de universidade. Cabe ainda salientar que diante de tão variada gama de informações, o aluno precisa desenvolver um apurado senso crítico, que o torne capaz de selecionar o material significativo e de boa qualidade para o desenvolvimento do seu trabalho.

\section{Writing Assignments in Physical Chemistry ${ }^{24}$}

A autora do referido trabalho observou que muitos estudantes matriculados na disciplina de fisico-química eram capazes de efetuar corretamente os cálculos exigidos para a resolução dos problemas apresentados nos exames. Entretanto, estes alunos frequentemente eram incapazes de compreender os processos físicos e químicos embutidos nas respostas. Por esta razão, L. Comeford ${ }^{24}$ sugere a adoção da leitura de textos de divulgação, atrelada a solicitação de tarefas escritas baseadas nesta leitura, como recurso capaz de diversificar a abordagem normalmente usada nesta disciplina. No tópico de química quântica, na disciplina de fisico-química, o livro In Search of Schrödinger's Cat: Quantum Physics and Reality foi usado com este propósito. Os capítulos do referido livro foram agrupados em três blocos e os alunos escreveram redações curtas ( 2 a 3 páginas) sobre cada um dos assuntos contidos nos blocos.

\section{Using "Household Chemistry Projects" To Develop Research Skills and To Teach Scientific Writing ${ }^{25}$}

O autor descreveu um projeto implementado na California State University, San Marcos, nomeado de "Projetos de Química com Materiais do Cotidiano". Era solicitado aos alunos 
que planejassem e colocassem em prática seus próprios projetos de pesquisa usando materiais e acessórios encontrados rotineiramente nas suas casas. A descrição da importância do projeto a ser executado, bem como os métodos usados na sua execução deviam ser apresentados ao professor, em forma de um manuscrito. Os manuscritos corrigidos eram publicados em um jornal chamado Journal of Household Chemistry e distribuídos para todos os estudantes no final do semestre.

\section{Teaching College General Chemistry: Techniques Designed To Communicate a Conceptual Framework ${ }^{26}$}

A disciplina de química geral, via de regra presente no currículo de alunos do curso de química e de estudantes de áreas correlatas, costuma apresentar-se como pouco atrativa para a maioria dos alunos nela matriculados. Considerando-se a importância do bom entendimento do conteúdo transmitido pelo professor nas aulas ministradas durante o desenvolvimento da disciplina, R.J. Duchovic ${ }^{26}$ apresenta neste artigo duas técnicas que se apresentaram como paliativas para a atenuação deste problema. Em uma delas, diretamente relacionada com o uso da escrita, solicitou-se aos alunos a redação de um total de quatro relatos escritos, durante um intervalo de quinze semanas. Em cada relato os estudantes deviam identificar e discutir os princípios químicos ou propriedades demonstradas para o grupo de estudantes no laboratório. Os relatos deviam também mencionar pontos de conexão entre o material discutido na sala de aula e as observações feitas no laboratório.

\section{A Capstone Writing Experience in Polymer Chemistry: Writing a Proposal For An Instrument Purchase ${ }^{27}$}

A estratégia descrita neste artigo tinha por objetivo integrar o conteúdo teórico transmitido em sala de aula a situações corriqueiras no dia-a-dia de profissionais envolvidos com a química dos materiais. A atribuição das tarefas escritas foi feita considerando que uma parte considerável da disciplina introdutória de química de polímeros aborda os vários métodos instrumentais para a caracterização dos mesmos. Aos alunos foi solicitada a redação de um artigo sobre um método instrumental por eles escolhido. Este artigo devia ser apresentado como uma proposta formal, considerando os prós e os contras da compra de um determinado modelo de um dado equipamento.

\section{CONSIDERAÇÕES FINAIS}

O número de exemplos de estratégias de ensino aqui apresentado é extremamente restrito quando comparado à enorme gama de trabalhos desta natureza encontrados na literatura. Porém, serve para ilustrar vários benefícios que podem ser extraídos a partir do uso da linguagem escrita, tanto em sala de aula como em aulas de laboratório de química. Algumas outras colocações podem ainda ser feitas a favor do uso da linguagem escrita:

- De uma maneira geral, o professor encontra-se muito mais inteirado sobre o nível de assimilação e sobre as concepções dos alunos, no que diz respeito aos tópicos ensinados, a partir da leitura de tarefas escritas similares às apresentadas aqui do que pela simples correção das populares questões de múltipla escolha ou questões do tipo "falso ou verdadeiro"; - Pensamento e linguagem encontram-se imbricados - quando um deles é aprimorado, o outro quase sempre melhora. Assim, quando se solicita ao aluno que escreva algo, impinge-se a ele a tarefa de "pensar" sobre este assunto, pois o ato de escrever envolve muito mais do que simplesmente expor idéias armazenadas na cabeça. Para tanto, fazse necessário que as idéias sejam repensadas e organizadas, para finalmente serem expostas.

Cabe ainda considerar aqui alguns aspectos do uso da linguagem escrita em sala de aula e laboratório que são preocupantes e até mesmo desestimulantes do ponto de vista de alguns pesquisadores ${ }^{28}$. Um deles é o maior tempo usualmente dispendido na elaboração, execução e correção das referidas tarefas escritas (insistindo-se no uso da linguagem escrita, não se estaria gastando um tempo precioso que poderia ser usado para, de fato, ensinar os princípios e conceitos da ciência? A bagagem científica dos alunos não seria prejudicada pela prática de tarefas escritas?). Um outro aspecto preocupante considera a própria formação do professor de química que foi treinado para ensinar ciências e não para discorrer com maestria sobre gramática, retórica, estruturação de frases, etc. Assim, um fino ajuste de vários fatores faz-se necessário quando se pretende trabalhar com linguagem escrita em salas de aulas ou em laboratórios de ciências.

\section{AGRADECIMENTO}

A autora agradece à Prof. Dra. Maria José P.M. de Almeida (Departamento de Metodologia de Ensino - Faculdade de Educação - UNICAMP) pelas sugestões.

\section{REFERÊNCIAS}

1. Emig, J.; J. Coll. Comp. Commun. 1977, 26, 122.

2. Thall, E.; Bays, G.; J. Chem. Educ. 1989, 66, 662.

3. Strauss, M.; Fulwiler, T.; J. Coll. Sci. Teach. 1987, 256.

4. Rosenthal, L. C.; J. Chem. Educ. 1987, 64, 996.

5. Shires, N. P.; J. Chem. Educ. 1991, 68, 494, e referências aí contidas.

6. Strauss, M.; Fulwiler, T.; J. Coll. Sci. Teach. 1990, 158.

7. Beall, H.; J. Chem. Educ. 1991, 68, 148.

8. Harwood, W. S.; J. Chem. Educ. 1996, 73, 229.

9. Beall, H.; J. Chem. Educ. 1993, 70, 10.

10. Meislich, E. K.; J. Chem. Educ. 1987, 64, 505.

11. VanOrden, N.; J. Chem. Educ. 1987, 64, 506.

12. Bailey, D.; Markowicz, L.; J. Chem. Educ. 1983, 60, 467.

13. Olmstead, J.; J. Chem. Educ. 1984, 61, 798.

14. Hermann, C. K.; J. Chem. Educ. 1994, 71, 861.

15. Bailey, R. A.; Geisler, C.; J. Chem. Educ. 1991, 68, 150.

16. Stewart, B. Y.; J. Coll. Sci. Teach. 1989, 94.

17. Koprowski, J. L.; J. Coll. Sci. Teach. 1997, 133.

18. Sunderwirth, S. G.; J. Chem. Educ.1993, 70, 474

19. Cooper, M. M.; J. Chem. Educ.1993, 70, 476.

20. Combs, L. L.; J. Chem. Educ.1993, 70, 462.

21. Wilson, J. W.; J. Chem. Educ.1994, 71, 1019.

22. Beall, H.; J. Chem. Educ.1994, 71, 1056.

23. McGowan, C.; Sendall, P.; J. Chem. Educ.1997, 74, 391.

24. Comeford, L.; J. Chem. Educ.1997, 74, 392.

25. Schmidt, M. H.; J. Chem. Educ.1997, 74, 393.

26. Duchovic, R. J.; J. Chem. Educ.1998, 75, 856.

27. Hunter, A. D.; J. Chem. Educ.1998, 75, 1424.

28. Labianca, D. A.; Reeves, W. J.; J. Chem. Educ. 1985, 62, 400. 